\title{
TRANSCRIPTION OF INTERFERON STIMULATED GENES IN RESPONSE TO PORCINE RUBULAVIRUS INFECTION IN VITRO
}

\section{María del Rosario Flores-Ocelotl ${ }^{1}$, Nora Hilda Rosas-Murrieta ${ }^{2}$, Verónica Vallejo-Ruiz ${ }^{1}$, Julio Reyes-Leyva ${ }^{1}$, Irma Herrera-Camacho $^{2}$, Gerardo Santos-López ${ }^{1}$ *}

${ }^{1}$ Laboratorio de Biología Molecular y Virología, Centro de Investigación Biomédica de Oriente, Instituto Mexicano del Seguro Social, Puebla, México; ${ }^{2}$ Laboratorio de Bioquímica, Centro de Química, Instituto de Ciencias, Universidad Autónoma de Puebla, México.

Submitted: July 25, 2010; Approved: January 31, 2011.

\begin{abstract}
Porcine rubulavirus (PoRV) is an emerging virus causing meningo-encephalitis and reproductive failures in pigs. Little is known about the pathogenesis and immune evasion of this virus; therefore research on the mechanisms underlying tissue damage during infection is essential. To explore these mechanisms, the effect of PoRV on the transcription of interferon (IFN) pathway members was analyzed in vitro by semiquantitative RT-PCR. Ten TCID ${ }_{50}$ of PoRV stimulated transcription of IFN $\alpha$, IFN $\beta$, STAT1, STAT2, p48 and OAS genes in neuroblastoma cells, whereas infection with $100 \mathrm{TCID}_{50}$ did not stimulate transcription levels more than non-infected cells. When the cells were primed with IFN $\alpha$, infection with $1 \mathrm{TCDI}_{50}$ of PoRV sufficed to stimulate the transcription of the same genes, but 10 and $100 \mathrm{TCID}_{50}$ did not modify the transcription level of those genes as compared with non-infected and primed controls. MxA gene transcription was observed only when the cells were primed with IFN $\alpha$ and stimulated with 10 TCID50, whereas 100 TCID50 of PoRV did not modify the MxA transcription level as compared to non-infected and primed cells. Our results show that PoRV replication at low titers stimulates the expression of IFNresponsive genes in neuroblastoma cells, and suggest that replication of PoRV at higher titers inhibits the transcription of several members of the IFN pathway. These findings may contribute to the understanding of the pathogenesis of PoRV.
\end{abstract}

Key words: Porcine rubulavirus, Interferon, STAT, LPMV, Gene expression.

\section{INTRODUCTION}

Porcine rubulavirus (PoRV), also known as La Piedad Michoacán Mexico virus (LPMV) is an emerging paramyxovirus causing blue eye disease (BED) in swine, an endemic disease in Mexico characterized by nervous, respiratory, and reproductive signs, with corneal opacity (14, 21).

\footnotetext{
*Corresponding Author. Mailing address: Laboratorio de Biología Molecular y Virología, Centro de Investigación Biomédica de Oriente, Instituto Mexicano del Seguro Social; HGZ No. 5, Km. 4.5 Carretera Federal Atlixco-Metepec; 74360 Metepec, Puebla, México.; E-mail: gerardo.santos.lopez@gmail.com / gerardo.santos@imss.gob.mx
} 
PoRV is an enveloped virus constituted by a single stranded negative sense RNA genome of $15 \mathrm{~kb}$, which is divided into six genes that code for the structural proteins: nucleoprotein (NP), phosphoprotein $(\mathrm{P})$, matrix $(\mathrm{M})$, fusion $(\mathrm{F})$, hemagglutinin-neuraminidase $(\mathrm{HN})$ and large $(\mathrm{L})$ proteins $(1,14,20,22)$.

In recent works our group has reported the variability of the hemagglutinin-neuraminidase at both genetic and biochemical levels, which reveals an active way of variability in PoRV isolates $(3,19)$. This fact seems to be promoted by the selective pressure exercised by the immune system of pigs, which has been shown to be directed specially against HN protein (10).

In many viral diseases, the infection is controlled at the cellular level by type I interferon (IFN $\alpha / \beta$ ) produced in response to the presence of viral double stranded RNA (dsRNA). Recognition of IFN-I by its specific cell receptors activates the signaling pathway JAK-STAT that includes the signal transducers and activators of transcription STAT1 and STAT2. Upon phosphorylation, STAT1 and STAT2 form heterodimers that translocate to the nucleus, where they associate with p48 (IRF9) to induce the activation of several IFN responsive genes, including: dsRNA-dependent protein kinase R (PKR), 2'5' oligoadenylate synthetase (OAS) and myxovirus resistance protein $\mathrm{A}(\mathrm{MxA})$, leading together to inhibition of viral replication, transcription and protein expression (16).

It has been demonstrated that several rubulaviruses inhibit the IFN antiviral responses by sequestering or targeting STAT proteins for proteosomal degradation, i.e. SV5 targets STAT1 (25), HuPIV-2 targets STAT2 (15), MuV target STAT1 and STAT2 (12), while Mapuera virus sequesters STAT1 and STAT2 in the cytoplasm (9).

Little is known about the pathogenesis and immune response during PoRV infection. Investigation of the mechanisms underlying immune evasion by this virus is essential for understanding its pathogenesis. In order to explore the effect of PoRV on different host IFN genes we performed a series of infections in vitro to identify the possible role of this virus in the modulation of host IFN-stimulated genes.

\section{MATERIAL AND METHODS}

\section{Virus and cells}

LPM virus (1984) was replicated in pig kidney PK-15 and in human neuroblastoma SH-SY5Y cells. The cell cultures were maintained in high glucose Dulbecco's minimum essential medium (DMEM) (Sigma Chemicals, San Luis MO.,USA) supplemented with $10 \%$ fetal bovine serum (FBS), $100 \mathrm{U} / \mathrm{ml}$ penicillin and $100 \mathrm{mg} / \mathrm{ml}$ streptomycin. Nonessential amino acids and $8 \mathrm{mM}$ sodium pyruvate were added to the medium used for SH-SY5Y cell cultures. The infected supernatants in PK-15 cells were harvested and clarified by centrifugation at $3200 \mathrm{rpm}$ for $40 \mathrm{~min}$ at $4{ }^{\circ} \mathrm{C}(17)$.

\section{Virus titration}

The viral titers were determined on PK-15 cell monolayers by means of the $\mathrm{TCID}_{50}$ standard method and calculated using the Reed-Muench protocol (2).

\section{PoRV infection on cells}

SH-SY5Y cells were seeded in 35-mm culture plates with DMEM-10\% FBS and incubated at $37{ }^{\circ} \mathrm{C}$ during $24 \mathrm{~h}$. Cells were then treated (primed) with $2000 \mathrm{IU} / \mathrm{ml}$ human recombinant IFN- $\alpha 2 b$ (Probiomed, Mexico City) in DMEM without serum during $5 \mathrm{~h}$. After that, unprimed and IFNprimed cells were inoculated with PoRV at different infectious doses $\left(1,10\right.$, and 100 TCID $\left._{50}\right)$. Non-infected cells, both primed and unprimed, were used as controls.

\section{Transcription of viral and cellular genes}

Mock and IFN-primed SH-SY5Y cells seeded on 35-mm plates were infected with PoRV. Total RNA was extracted at 48 h p.i. using Trizol reagent (Invitrogen, Carlsbad, CA) and 
treated with DNase I (Fermentas, Burlington, ON). cDNA was synthesized and amplified by RT-PCR using SuperScript II One-Step RT-PCR System with Platinum Taq (Invitrogen, Carlsbad, CA) according to manufacturer's instructions. Primers for cellular genes and conditions for RT-PCR reactions were obtained from previous reports $(7,18)$. The housekeeping gene cyclophilin (CP) was used as an internal control. Amplified products were analyzed by electrophoresis on a $2 \%$ agarose gel. Images were captured in a Kodak EDAS 290 LE system (Eastman Kodak Co., Rochester, NY) and analyzed with Quantity-One software (Bio-Rad, Hercules, CA). Results were reported as optical density gene/CP ratios. The obtained data were analyzed using the non-parametric Kruskal-Wallis and Mann-Whitney U tests. The values were reported as means of three replicates \pm standard deviation; significance was set at
$\mathrm{P}<0.05$.

\section{RESULTS}

\section{Effect of IFN- $\alpha$ on the PoRV infection}

To determine the possible antiviral effect of IFN- $\alpha$ against PoRV we infected IFN primed or mock PK-15 cells with different doses: 1, 10 and $100 \mathrm{TCID}_{50}$, and the viral titers in supernatants were determined at $48 \mathrm{~h}$, p.i. Figure 1 shows that infection with 1 TCID $_{50}$ PoRV induced a low infectious titer that was eliminated when the cells were treated with IFN, whereas in the infection with $10 \mathrm{TCID}_{50}$ the IFN decreased in 1 $\log$ the viral titers and, at $100 \mathrm{TCID}_{50}$, the difference between IFN-treated and mock infected cells was circa $0.5 \mathrm{log}$.

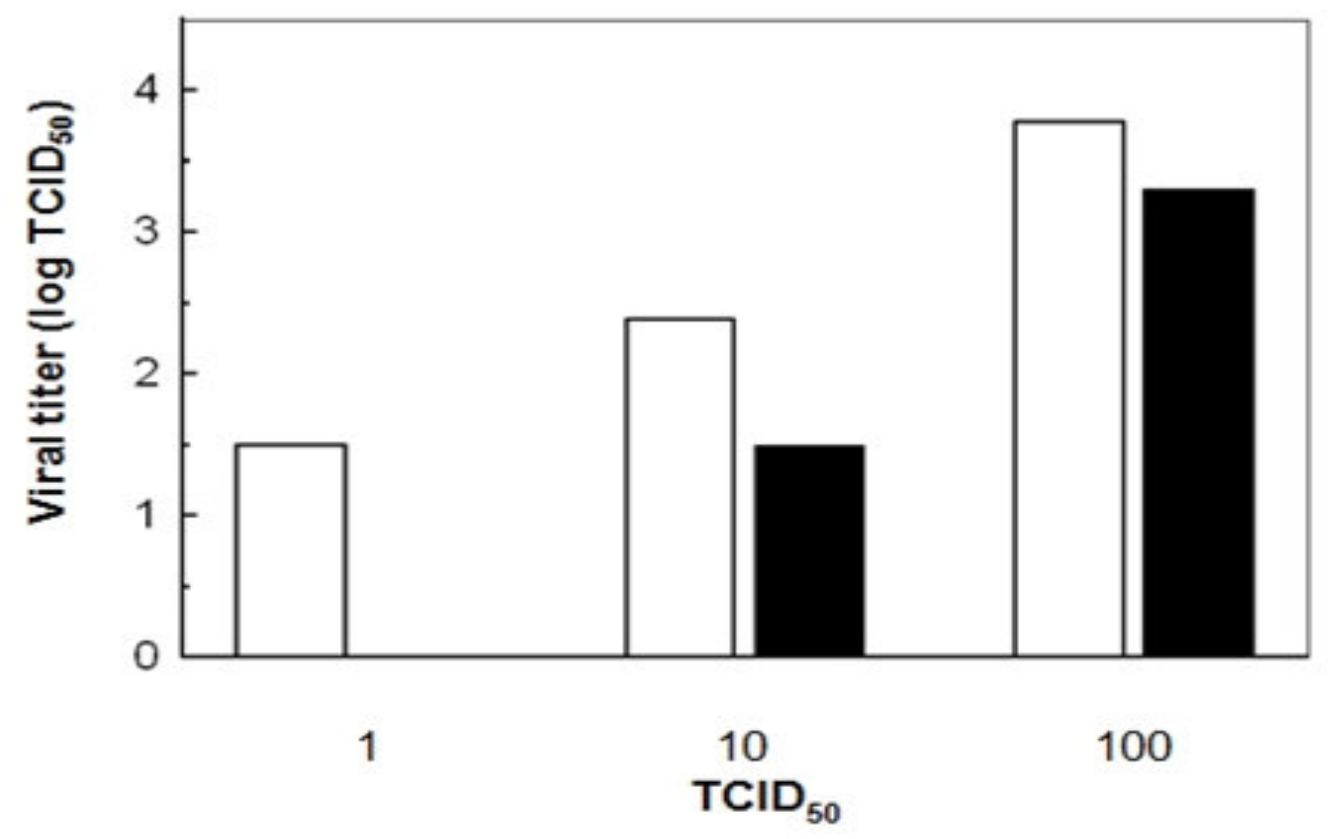

\section{$\square$ No IFN-primed control $\square$ IFN-primed cells}

Figure 1. Effect of IFN $\alpha$ on the PoRV replication in SH-SY5Y cells. PoRV was inoculated in IFN $\alpha$-primed or unprimed SHSY5Y cells and TCID $_{50}$ titers were determined at $48 \mathrm{~h}$ post-infection. 


\section{Transcriptional levels of IFN $\alpha$ and IFN $\beta$ genes}

The transcription of some IFN responsive genes was analyzed to identify if viral infection modifies the antiviral response. Fig. 2A shows that unprimed neuroblastoma cells presented a basal level of IFN $\alpha$ transcript that was enhanced when cells were infected with $10 \mathrm{TCID}_{50}$, however when the infection was performed using $100 \mathrm{TCID}_{50}$ the transcription level was not modified respect to the basal values. In the case of IFN $\beta$, the transcript was undetectable in uninfected control cells and it was stimulated by the presence of the virus, increasing according to viral doses.

When the cells were primed with IFN some differences were observed (Figure 2B). Both IFN $\alpha$ and IFN $\beta$ genes were transcribed in uninfected cells and enhanced when the cells were infected with only 1 TCID $_{50}$. When we used a higher viral titer the IFN $\alpha$ gene transcription was comparable with the control level, whereas IFN $\beta$ gene transcription presented lower levels than the control.
A

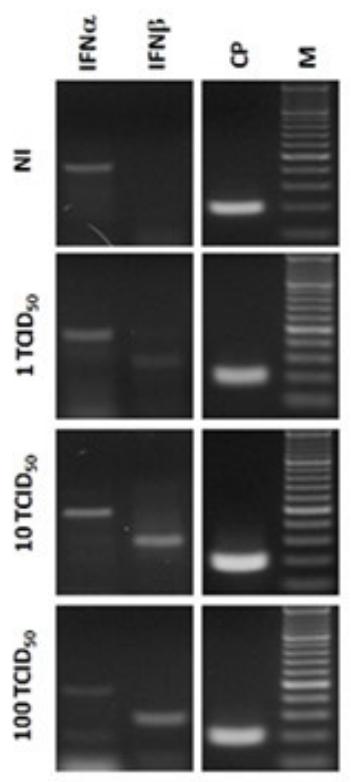

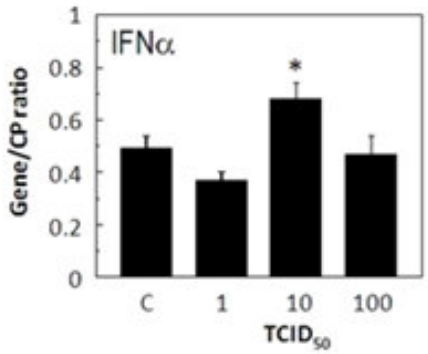

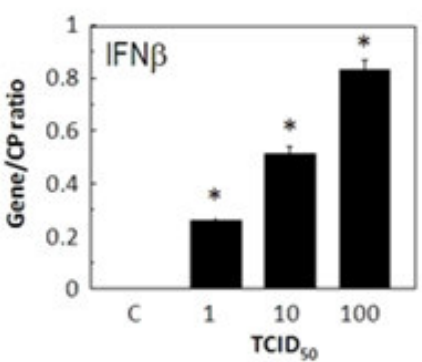

B

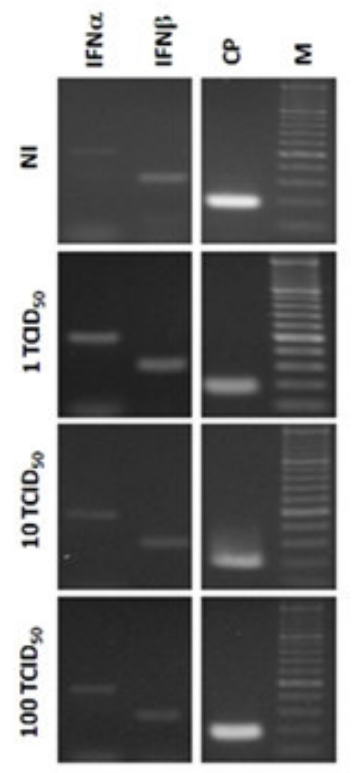

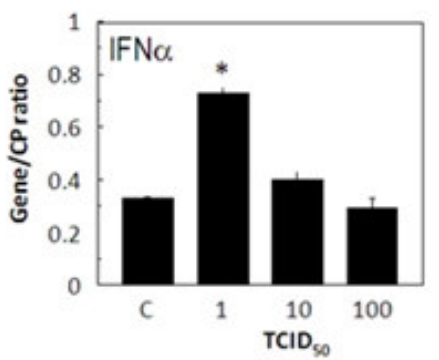

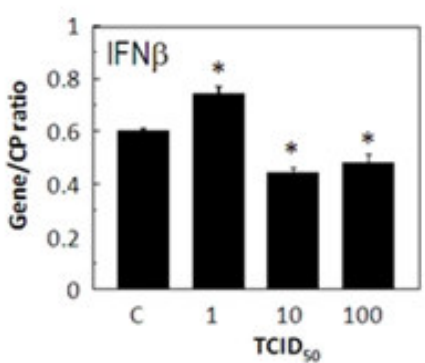

Figure 2. Tanscription levels of IFN $\alpha$ and IFN $\beta$ genes. PoRV was inoculated at 1, 10 and 100 TCID $_{50}$ into unprimed (A) or IFN-primed SHSY-5Y cells (B). Specific segments of IFN $\alpha$ and IFN $\beta$ sequences were amplified by RT-PCR on total RNA extracted from infected or uninfected cells and analyzed by means of agarose gel electrophoresis and densitometry. Data represents the mean of three experiments \pm standard deviation. In the gel, CP indicates the RT-PCR amplicon of the cellular house-keeping gene cyclophilin and M the molecular marker (100 pb ladder). * $\mathrm{P}<0.05$ compared with uninfected control infection.

\section{Transcriptional levels of ISGF3 components}

To determine the possible interference of the virus in IFN signaling, we analyzed the transcription levels of the three components of ISGF3: STAT1, STAT2 and p48. All these genes presented a basal level of transcription that was stimulated when the cells were infected (Figure 3A). This increase was evident during the infection with 10 TCID $_{50}$ PoRV, whereas with $100 \mathrm{TCID}_{50}$ the transcription levels were 
reduced to basal values. In contrast, the IFN-primed cells showed that the transcripts of the three genes were increased when they were infected using 1 TCID $_{50}$ only, and the levels were lower when higher viral titers were used, which were comparable with basal levels of transcription (Figure 3B).
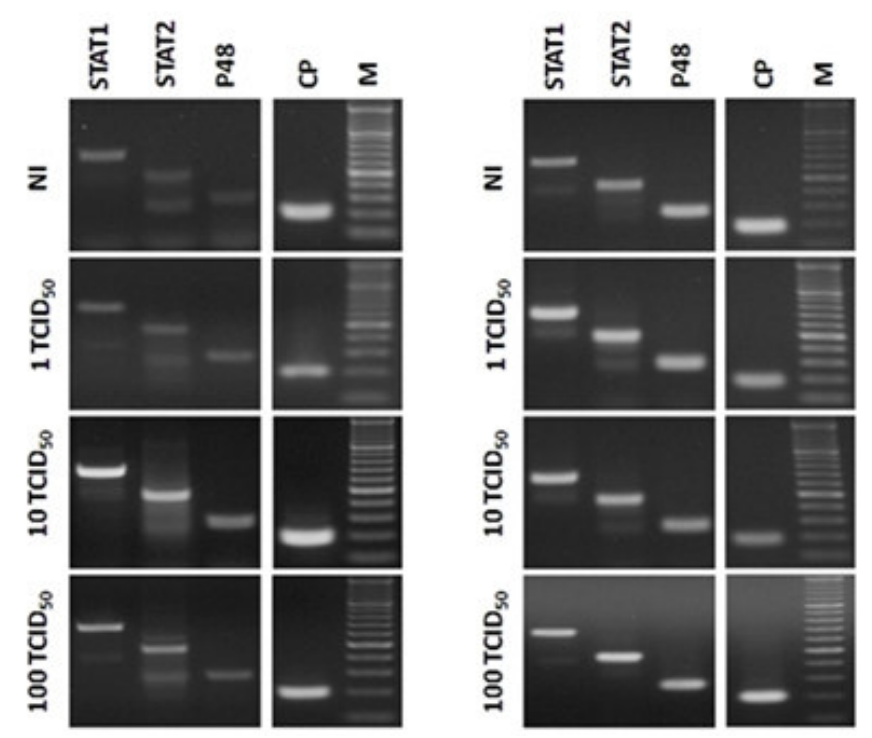

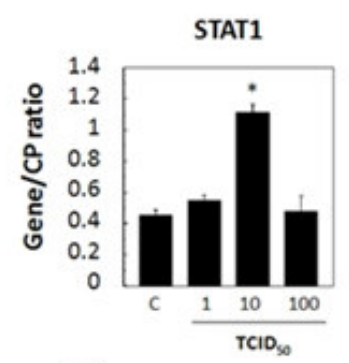

STAT2
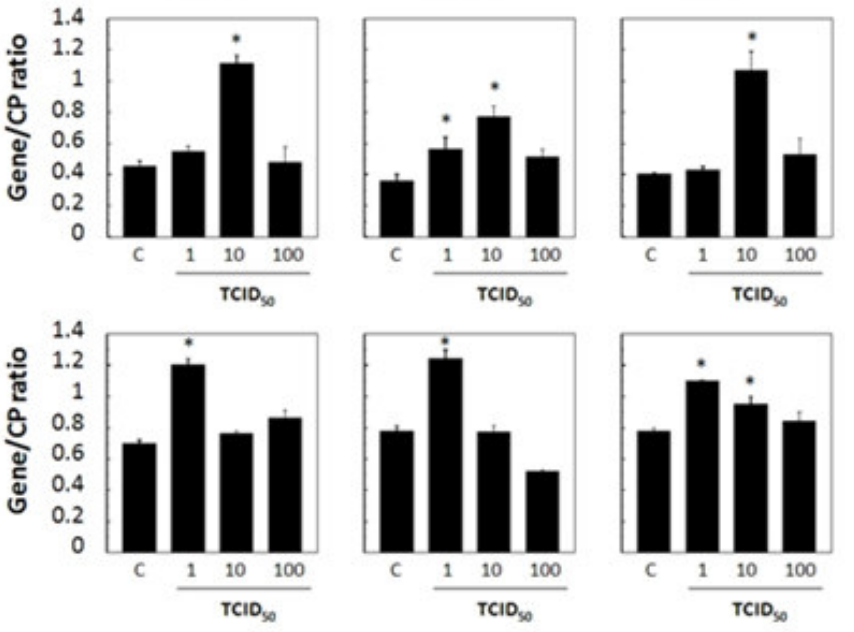

Figure 3. Tanscription levels of STAT1, STAT2 and p48 genes. PoRV was inoculated at 1, 10 and 100 TCID50 into unprimed (A) of IFN-primed SHSY-5Y cells (B). Specific fragments of STAT1, STAT2 and p48 sequences were amplified by RT-PCR on total RNA extracted from infected or uninfected cells and analyzed by means of agarose gel electrophoresis and densitometry. Data represents the mean of three experiments. ${ }^{*} \mathrm{P}<0.05$ compared with uninfected control.

\section{Transcriptional levels of IFN responsive effector proteins}

A major cell resource against viral infections is a group of proteins with direct antiviral activities, such as OAS, PKR and MxA. The transcription levels and activation by PoRV infection in neuroblastoma cells was different in this group of genes: OAS had a basal level in uninfected cells that was stimulated when the cells were infected with $10 \mathrm{TCID}_{50}$ and decreased to basal values when $100 \mathrm{TCID}_{50}$ was used (Figure 4). In contrast, basal PKR transcription was not modified by the PoRV infection. In the case of MxA, the RT-PCR product was not observed in either infected or uninfected cells.

When IFN-primed cells were analyzed, a different expression pattern was observed. The transcription of OAS was similar to that of STAT1, STAT2, and p48 genes, which showed a more activated transcription using only $1 \mathrm{TCID}_{50}$ in IFN treated cells and reducing the transcription levels with a trend to basal values when the cells were infected with 10 and $100 \mathrm{TCID}_{50}$ (Figure 4B). On the other hand, the transcription level of PKR in uninfected IFN-primed cells is similar to unprimed cells, although the infection had a stimulating effect on the transcription, which was slightly modified when the cells were infected with 1,10 or 100 $\mathrm{TCID}_{50}$. A different pattern corresponds to the MxA transcription, which was not detected in unprimed cells, however the IFN treatment stimulated its transcription. The virus infection enhanced the MxA transcription when $10 \mathrm{TCID}_{50}$ was used, and reducing it to basal levels when using $100 \mathrm{TCID}_{50}$.

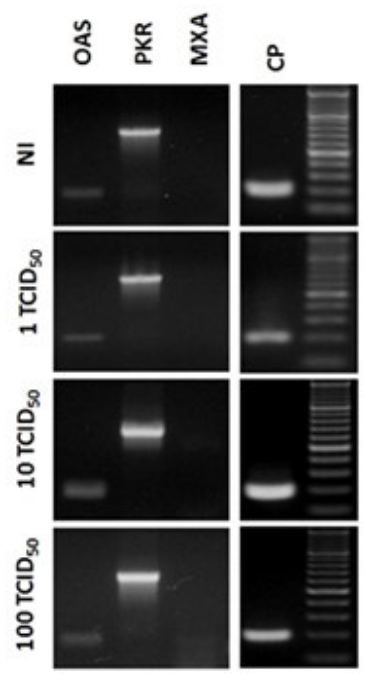



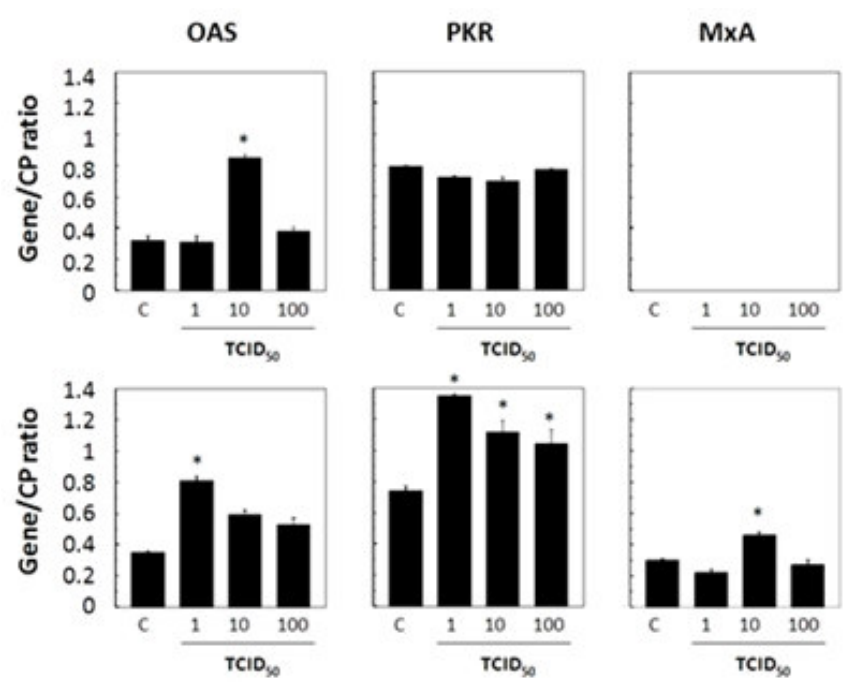

Figure 4. Tanscription levels of OAS, PKR and MxA genes. PoRV was inoculated at 1,10 and 100 TCID $_{50}$ into unprimed (A) or IFN-primed SHSY-5Y cells (B). Specific segments of OAS, PKR and MxA sequences were amplified by RT-PCR on total RNA extracted from infected or uninfected cells and analyzed by means of agarose gel electrophoresis and densitometry. Data represents the mean of three experiments. $* \mathrm{P}<0.05$ compared with uninfected control infection.

\section{DISCUSSION}

The IFN system is a key event in the establishment of the antiviral state of the cell. Many viruses have the ability to inhibit this response, i.e. paramyxoviruses, which interfere with several proteins related with this process (16). To explore the mechanisms of pathogenesis in PoRV infection we used a semi-quantitative RT-PCR test to analyze the relative expression of several genes involved in the type I interferon pathway. This protocol has demonstrated to be efficient in a preview study, where we determined the expression of the same or similar genes which are involved in the establishment of antiviral state in the cells (18).

According to the present results, in vitro PoRV replication is inhibited by IFN $\alpha$, although the effect is reduced when a higher titer of PoRV was used to infect the cells. This fact suggests that PoRV could inhibit some factors of the IFN pathway, as has been reported for other paramyxoviruses (16). These probable events were analyzed by a semi-quantitative RT-PCR in order to explore the transcription rate of several genes involved in the IFN response.

In our experiments, PoRV was not able to activate or to stimulate the transcription of most analyzed genes when a low dose of $1 \mathrm{TCID}_{50}$ was used in the infections on IFN-unprimed cells. It was necessary to inoculate the cells with $10 \mathrm{TCID}_{50}$ to observe a stimulatory effect. Nevertheless, the cells infected with higher doses of virus $\left(100 \mathrm{TCID}_{50}\right)$ experience an apparent inhibitory effect on the transcription of these genes. The exception was IFN $\beta$ gene, that showed an increasing level of transcription depending on the viral titer, including the infection with 1 TCID $_{50}$, which was not detected in uninfected cells. Several works have shown that IFN $\beta$ transcription is strongly regulated and RNAm is not detected (24) and this gene needs a higher order transcription enhancer complex with multiple transcription factors, which are stimulated by a virus infection $(6,23)$.

When the cells were infected with 10 TCID $_{50}$, activation was observed in most genes, which indicates that cells have processed the different inducers of IFN signals, which in turn depends on virus availability. However when the cells were infected with a high titer of PoRV $\left(100 \quad \mathrm{TCID}_{50}\right)$ the transcription levels of almost all genes were decreased to basal values, which suggests that some anti-IFN viral factor could be acting in the infected cells. This anti-IFN effect is typical in paramyxoviruses, such as mumps $(12,18)$, simian virus $5(25$, 26) and other parainfluenzaviruses $(5,13)$.

On the other hand, when the infection was performed on IFN-primed cells, the transcription of most genes increased when 1 TCID $_{50}$ was used, in contrast with unprimed cells, which presented the highest transcription at $10 \mathrm{TCID}_{50}$. These data suggest that primed cells are more effective to respond against PoRV infection since a lower viral titer suffices to increase the transcription of studied genes. 
The anti-IFN effects of paramyxoviruses has been associated with the expression of the $\mathrm{V}$ protein, coded in the $\mathrm{P} / \mathrm{V}$ gene and expressed by a co-transcriptional edition of the $\mathrm{P}$ protein open reading frame $(4,8,11)$. The mechanism by which PoRV inhibits the transcription of these genes is still unknown; however, since it belongs to the Rubulavirus genus it is possible that the $\mathrm{V}$ protein is involved in these effects.

The $\mathrm{V}$ protein has been characterized as an anti-IFN resource during paramyxovirus infections. This protein has a direct effect on the JAK-STAT signaling unchained by IFN. The precise role of the $\mathrm{V}$ protein is generated by the interaction with STAT members, which are sequestered or targeted for degradation, inhibiting in this way the activation of the antiviral genes primed by $\operatorname{IFN}(9,12,25)$.

In a recent work our group showed a differential effect of the $\mathrm{V}$ protein during $\mathrm{MuV}$ infection in vitro (18). A viral clone obtained from the Urabe AM9 vaccine presents three G nucleotides in the $\mathrm{P} / \mathrm{V}$ edition site, producing the insertion of a glycine residue in its $\mathrm{V}$ protein. The replication and interferon sensitivity levels of this virus were deficient when it was compared with another viral clone obtained from the same vaccine, that did not present this Gly insertion. These results suggest that the deficient replication of the $\mathrm{MuV}$ with Gly insertion is influenced by its sensitivity to interferon and its capacity to reduce the antiviral response.

In the case of PoRV, there is no information available about the possible mechanisms of blocking IFN activity. The antiviral activity of any of the virus factors is involved in decreasing the transcription levels of members of the IFN pathway; however, other experiments will be necessary to determine the precise mechanism of this phenomenon. These experimental procedures must involve protein expression studies, analysis of activation or inactivation by phosphorilation of STAT proteins or blocking of the translocation of transcription factors, among other evidences.

Summarizing, PoRV has the ability of inhibiting some components of the IFN pathway, which may negatively influence the antiviral-response in the host and might contribute to its pathogenicity.

\section{ACKNOWLEDGMENTS}

RFO was supported by fellowships of CONACyT (189919) and IMSS (99224528).

\section{REFERENCES}

1. Berg, M.; Bergvall, A.C.; Svenda, M.; Sundqvist, A.; Moreno-Lopez, J.; Linne, T. (1997). Analysis of the fusion protein gene of the porcine rubulavirus LPMV: comparative analysis of paramyxovirus $\mathrm{F}$ proteins. Virus Genes 14(1),55-61.

2. Blake, K.; O'Connell, S. (1993). Virus Culture. In D.R. Harper (ed.), Virology, Lab Fax. Bios Scientific Publishers. Oxford. p. 81-122.

3. Borraz-Arguello, M.d.T.; Santos-Lopez, G.; Vallejo-Ruiz, V.; HerreraCamacho, I.; Reyes-Leyva, J. (2008). [Biological characterization of three natural isolates of the porcine rubulavirus (Mexico)]. Rev Biol Trop 56(2),487-99.

4. Childs, K.; Stock, N.; Ross, C.; Andrejeva, J.; Hilton, L.; Skinner, M.; Randall, R.; Goodbourn, S. (2007). mda-5, but not RIG-I, is a common target for paramyxovirus V proteins. Virology 359(1),190-200.

5. Choudhary, S.; Gao, J.; Leaman, D.W.; De, B.P. (2001). Interferon action against human parainfluenza virus type 3: involvement of a novel antiviral pathway in the inhibition of transcription. $J$ Virol 75(10),482331.

6. Falvo, J.V.; Parekh, B.S.; Lin, C.H.; Fraenkel, E.; Maniatis, T. (2000). Assembly of a functional beta interferon enhanceosome is dependent on ATF-2-c-jun heterodimer orientation. Mol Cell Biol 20(13),4814-25.

7. Fujii, N.; Yokosawa, N.; Shirakawa, S. (1999). Suppression of interferon response gene expression in cells persistently infected with mumps virus, and restoration from its suppression by treatment with ribavirin. Virus Res 65(2),175-85.

8. Gotoh, B.; Komatsu, T.; Takeuchi, K.; Yokoo, J. (2002). Paramyxovirus strategies for evading the interferon response. Rev Med Virol 12(6),33757.

9. Hagmaier, K.; Stock, N.; Precious, B.; Childs, K.; Wang, L.F.; Goodbourn, S.; Randall, R.E. (2007). Mapuera virus, a rubulavirus that inhibits interferon signalling in a wide variety of mammalian cells without degrading STATs. J Gen Virol 88(Pt 3),956-66.

10. Hernandez, J.; Reyes-Leyva, J.; Zenteno, R.; Ramirez, H.; HernandezJauregui, P.; Zenteno, E. (1998). Immunity to porcine rubulavirus infection in adult swine. Vet Immunol Immunopathol 64(4),367-81. 
12. Kiyotani, K.; Sakaguchi, T.; Kato, A.; Nagai, Y.; Yoshida, T. (2007). Paramyxovirus Sendai virus V protein counteracts innate virus clearance through IRF-3 activation, but not via interferon, in mice. Virology 359(1),82-91.

12. Kubota, T.; Yokosawa, N.; Yokota, S.; Fujii, N. (2002). Association of mumps virus $\mathrm{V}$ protein with RACK1 results in dissociation of STAT-1 from the alpha interferon receptor complex. $J$ Virol 76(24),12676-82.

13. Leroy, M.P.; Baise, E.A.; Pire, G.A.; Desmecht, D.J. (2007). Contribution of MX dynamin, oligoadenylate synthetase, and protein kinase $\mathrm{R}$ to anti-paramyxovirus activity of type 1 interferons in vitro. Am $J$ Vet Res 68(9),988-94.

14. Moreno-Lopez, J.; Correa-Giron, P.; Martinez, A.; Ericsson, A. (1986). Characterization of a paramyxovirus isolated from the brain of a piglet in Mexico. Arch Virol 91(3-4),221-31.

15. Nishio, Y.; Noguchi, E.; Ito, S.; Ichikawa, E.; Umebayashi, Y.; Otsuka, F.; Arinami, T. (2001). Mutation and association analysis of the interferon regulatory factor 2 gene (IRF2) with atopic dermatitis. J Hum Genet 46(11),664-7.

16. Randall, R.E.; Goodbourn, S. (2008). Interferons and viruses: an interplay between induction, signalling, antiviral responses and virus countermeasures. J Gen Virol 89(Pt 1),1-47.

17. Reyes-Leyva, J.; Hernandez-Jauregui, P.; Montano, L.F.; Zenteno, E. (1993). The porcine paramyxovirus LPM specifically recognizes sialyl (alpha 2,3) lactose-containing structures. Arch Virol 133(1-2),195-200.

18. Rosas-Murrieta, N.; Herrera-Camacho, I.; Vallejo-Ruiz, V.; MillanPerez-Pena, L.; Cruz, C.; Tapia-Ramirez, J.; Santos-Lopez, G.; ReyesLeyva, J. (2007). Differential sensitivity to interferon influences the replication and transcription of Urabe AM9 mumps virus variants in nerve cells. Microbes Infect 9(7),864-72.
19. Sanchez-Betancourt, J.I.; Santos-Lopez, G.; Alonso, R.; Doporto, J.M.; Ramirez-Mendoza, H.; Mendoza, S.; Hernandez, J.; Reyes-Leyva, J.; Trujillo, M.E. (2008). Molecular characterization of the hemagglutininneuraminidase gene of porcine rubulavirus isolates associated with neurological disorders in fattening and adult pigs. Res Vet Sci 85(2),35967.

20. Santos-López, G.; Hernández, J.; Borraz-Argüello, M.T.; Ramírez Mendoza, H.; Vallejo, V.; Reyes-Leyva, J. (2004). [Proteins of Porcine rubulavirus: Structure, function and pathological implications]. Arch Med Vet 36(2),119-136.

21. Stephan, H.A.; Gay, G.M.; Ramirez, T.C. (1988). Encephalomyelitis, reproductive failure and corneal opacity (blue eye) in pigs, associated with a paramyxovirus infection. Vet Rec 122(1),6-10.

22. Sundqvist, A.; Berg, M.; Hernandez-Jauregui, P.; Linne, T.; MorenoLopez, J. (1990). The structural proteins of a porcine paramyxovirus (LPMV). J Gen Virol 71 ( Pt 3),609-13.

23. Thanos, D.; Maniatis, T. (1995). Identification of the rel family members required for virus induction of the human beta interferon gene. Mol Cell Biol 15(1),152-64.

24. Tovey, M.G.; Streuli, M.; Gresser, I.; Gugenheim, J.; Blanchard, B.; Guymarho, J.; Vignaux, F.; Gigou, M. (1987). Interferon messenger RNA is produced constitutively in the organs of normal individuals. Proc Natl Acad Sci U S A 84(14),5038-42.

25. Ulane, C.M.; Horvath, C.M. (2002). Paramyxoviruses SV5 and HPIV2 assemble STAT protein ubiquitin ligase complexes from cellular components. Virology 304(2),160-6.

26. Young, D.F.; Didcock, L.; Goodbourn, S.; Randall, R.E. (2000). Paramyxoviridae use distinct virus-specific mechanisms to circumvent the interferon response. Virology 269(2),383-90. 
